\title{
Erratum: Quadricuspid pulmonic valve found on well exam
}

Stephen N. Dunay", Eric A. Roberge and Lena S. Avedissian

\section{Erratum}

After publication of this work [1], we noted the second author's name was incorrect as Robert A Roberge. The author's correct name should be Eric A Roberge.

Received: 11 June 2015 Accepted: 11 June 2015

Published online: 27 June 2015

\section{Reference}

1. Dunay SN, Roberge RA, Avedissian LS. Quadricuspid pulmonic valve found on well exam. Mil Med Res. 2015;2:10.

* Correspondence: stephen.dunay@gmail.com

Madigan Army Medical Center, 9040 Jackson Avenue, Tacoma, WA 8431, USA

Submit your next manuscript to BioMed Central and take full advantage of:

- Convenient online submission

- Thorough peer review

- No space constraints or color figure charges

- Immediate publication on acceptance

- Inclusion in PubMed, CAS, Scopus and Google Scholar

- Research which is freely available for redistribution

Submit your manuscript at www.biomedcentral.com/submit 